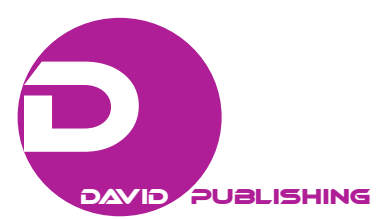

\title{
Challenge of Implementing Balanced Scorecard Strategy in Saudi Arabia
}

\author{
Salwa Abdullah Alhamoudi \\ Institute of Public Administration, Riyadh, Saudi Arabia
}

\begin{abstract}
A balanced scorecard (BSC) is ideally created through a shared understanding and translation of an organisation's strategy into objectives, measures, targets, and initiatives in each of four scorecard perspectives. However, BSC implementation is not without challenges. This study is an exploratory investigation into the BSC implementation and the critical factors addressed in the real world. This research attempts to investigate the critical success factors (CSFs) of BSC implementation in organisations that have already implemented it. A survey research method based on quantitative technique was used, with a sample size of 250 candidates from five organisations. The study identifies 10 main critical factors that must be carefully considered in BSC implementation to achieve a successful project. This study highlights that BSC perspectives, top management support, the BSC team, clear mission, and strategy were viewed as the most critical success factors. The choice of perspectives for the organisation's BSC must adhere to what is necessary to execute the strategy and create a competitive advantage for the organisation. The BSC measures must be linked to the strategic objectives of the organisation. The BSC team has to be supported continuously by top management to enable them to sustain and maintain the BSC.
\end{abstract}

Keywords: balanced scorecard, performance measurement, critical success factors, BSC implementation, strategy development, case study

\section{Introduction to Balance Scorecard (BSC)}

Measuring organisational success and implementing effective strategies for future success represent continuous challenges for managers, researchers, and consultants. Traditional performance measurement does not reflect performance in the new economy, in which non-financial measures appear more significant (Jochem, Menrath, \& Landgraf, 2010). Internally, the activities that create shareholder value must be identified and managed. Externally, investors need to assess value creation. Internal and external needs can be served by appropriate metrics that capture and communicate activities linked to strategy and vision (Wang, 2005).

One of the modern performance measurement systems introduced in the 1990s was the balanced scorecard (BSC). The balanced scorecard is ideally created through a shared understanding and translation of the organisation's strategy into objectives, measures, targets, and initiatives in each of the four scorecard perspectives (Niven, 2008).

Whereas some scholars focus their analysis on the financial performance consequences of BSC adoption,

Salwa Abdullah Alhamoudi, Dr., assistant professor, director of Research and Consultation Department, Institute of Public Administration, Riyadh, Saudi Arabia.

Correspondence concerning this article should be addressed to Salwa Abdullah Alhamoudi, Institute of Public Administration, Riyadh 11141, Saudi Arabia. 
others place their emphasis on BSC's role as a strategic management tool. Kaplan and Norton (1996; 2001) have claimed that BSC users have benefited from using BSC as a strategic management system, as it helps translate vision and strategy into key performance indicators (KPIs), communicate strategy to employees at lower levels, and make strategy for everybody's everyday job.

Similar to any other management tool, the success and failure of the BSC's implementation very much depend on various factors. The research by the Hackett Group (2004) found that overall: nearly two-thirds of typical companies had some type of BSC programme in place or in development. However, Hackett found that only $17 \%$ of all typical companies had developed mature BSC that relied on a mix of financial and operational metrics. World-class companies are $159 \%$ more likely to have reached this level in their balanced scorecard efforts - but even at world-class companies, only 44\% have achieved this goal. According to Hackett's research, this suggests that most companies are having significant difficulty taking balanced scorecards from concept to reality. The importance of this study, it sheds light on the success factors of change in performance measurement practices in an organisational context, as well as enhancing our understanding of the ways in which an integrated performance measurement system such as the BSC operates. The aim of this study is to develop a better understanding of the process of BSC implementation, by identifying the critical factors of the BSC project, and assessing their effectiveness in the implementation. The main research question is what are the critical factors for effective BSC implementation.

This research provides a review of the relevant literature from numerous fields of study associated with BSC concepts. This will be clarified firstly by an overview of the BSC concept and the BSC process and perspectives. The second part explains the research methodology of the study, the data collection techniques adopted. The third part explains the data analysis techniques for quantitative method. In addition, issues of reliability and validity in the research methodology are also discussed. The fourth part explains the result of the research and the ranking analysis of the CSFs. In the final part, discussion and conclusion of the research are presented.

\section{Theoretical Background}

\section{BSC From Performance Measurements to Performance Management}

Management requires internal and external measures of success factors according to Kaplan and Norton (1996). They maintain that "if companies are to survive and prosper in information age competition, they must use measurement and management systems derived from their strategies and capabilities". They further add that what cannot be measured cannot be managed. An organisation's measurement system strongly affects the behaviour of personnel both inside and outside the organisation. Traditional PM does not reflect performance in the new economy, in which non-financial measures appear more significant. Internally, the activities that create shareholder value must be identified and managed. Externally, investors need to be able to assess value creation. Internal and external needs can be served by appropriate metrics that capture and communicate activities linked to strategy and vision (Valiris, Chytas, \& GlyKas, 2005; Wang, 2005).

Performance measurements (PM) systems were established as a means of monitoring and maintaining organisational control (Tyagi \& Gupta, 2008), the process of ensuring that an organisation implements strategies that lead to the achievement of overall goals and objectives (Tyagi \& Gupta, 2008). Davis and Albright (2004) argue that the PM systems were historically established for monitoring and maintaining organisational control, which is the process of certifying that an organisation follows strategies that guide it to the attainment of overall goals and objectives (Jochem et al., 2010). Other researchers suggested that a PM 
system could provide organisations with more dependable tools for managing change (Ho, Cheng, \& Lin, 2001; Davis \& Albright, 2004). In addition, it can provide motivation and direction, give feedback on the effectiveness of plans and their implementation, and help in strategy formulation and revision (Ho et al., 2001).

Davis and Albright (2004) mentioned that initial PM practices fulfilled two objectives. First, they conveyed information to managers to demonstrate the nature and status of work finished and contributed to enhanced work productivity. Secondly, they supported budgetary decision-making by revealing information about needs and programme effectiveness.

Amaratunga and Baldry (2002), however, argue that measurement is not an end in itself, but a tool for more effective management. Results of PM show what happened, not why it happened, or what to do about it. An organisation has to make effective use of its PM outcomes; it has to be able to formulate the transition from measurement to management. It also has to be able to anticipate needed changes in the strategic direction of the organisation and have a methodology in place for effecting strategic change (Brewer, Albright, \& Davis, 2004). This concept is identified as performance management in PM literature.

Jochem et al. (2010) concluded that performance measurement and performance management are not separable. They also believed that performance management carries a philosophy that might be supported by performance measurement. Organisations which do not integrate ongoing performance measurement and feedback into their management development programmes tend to experience lower satisfaction and higher turnover than would be expected with the measures which are being introduced to improve performance (Tyagi $\&$ Gupta, 2008). Jochem et al. (2010) stated that a performance measurement system is designed to support the company's decision-making process through target-oriented indicators that can be compared with the existing best practices. However, Kaplan and Norton (2001) argue that the BSC has evolved as a framework for measuring organisation performance. However, they understood that measurement has consequences beyond just reporting on the past. Consequently, they developed the BSC concept from being a performance measurement system to becoming an organising framework for a strategic management system.

The BSC is a management system enabling organisations to explain their vision and strategy, and translate these into action. It provides feedback revolving around both the internal business processes and external outcomes to facilitate continuous improvement in strategic performance and results ( $\mathrm{Wu}, 2005)$. The balanced scorecard is ideally created through a shared understanding and translation of the organisation's strategy into objectives, measures, targets, and initiatives in each of the four scorecard perspectives (Kaplan \& Norton, 2008; Niven, 2008). According to the literature review, some studies attempted to examine the BSC from different role perspectives, first in a role of performance measurement, and second in a strategy implementation role (Ittner \& Larcker, 2003; Wu, 2005; Campbell, Datar, Kulp, \& Narayanan, 2015). Building on these two streams Campbell et al. (2015) examine whether and how a multidimensional performance measurement system can be used to distinguish between strategic problems related to strategic inputs, customer-oriented strategic outputs, and financial performance. They found that the company's internal performance measures systematically reveal more timely information about problems with the strategy. Furthermore, the performance measures can help identify where and why the strategy failed.

Among others, the BSC's implementation project requires substantial human and financial resources (Van Grembergen \& De Haes, 2005). The various outcomes of the BSC's projects show that the implementation is not a linear process, but a complex one. In addition, implementing the BSC in an organisation often resulted in changes in the organisational structure and system. 
Kaplan and Norton also enhanced the BSC concept to become an integrated performance framework, and this can be seen from their later publication from the year 1996 onwards. The BSC concept introduced in 1992 was redesigned to link the four perspectives of measures to the company's strategy. With this linkage, the BSC has been recognised as a tool to explicitly link 26 performance measurement systems to strategy and perhaps the most popular and widely implemented performance management system by organisations. Furthermore, the BSC was claimed to be the most influential or dominant concept of performance measurement (Geuser, Mooraj, \& Oyon, 2009). Subjective performance evaluation systems often prescribe for evaluators to use multiple measures to assess overall subordinate performance. Long, Mertins, and Vansant (2015) suggest firms should carefully consider what the structure and characteristics of their performance evaluation systems communicate to evaluators regarding the role of subjectivity.

One problem in reaching consensus on the factors that support the process of managing through measures is the broad range of approaches that different authors use (Assiri, 2006; Lueg \& Vu, 2015). Out of a review of the academic and practitioner literature, the present researcher found 10 relevant studies, the table below shows the most CSF's influencing the BSC.

Table 1

Summary of Literature Review Identifying Critical Success Factors (CSF) Influencing the BSC

\begin{tabular}{|c|c|c|}
\hline Reference & Research approach & Factors \\
\hline Kaplan and Norton (2001) & Case study & $\begin{array}{l}\text { Organisational culture } \\
\text { Reviewing } \\
\text { Communication } \\
\text { Management commitment } \\
\text { Compensation } \\
\text { Strategy focus } \\
\text { Target setting }\end{array}$ \\
\hline De Waal (2002) & Case study & $\begin{array}{l}\text { Organisational culture } \\
\text { Alignment } \\
\text { Review and update } \\
\text { Management commitment }\end{array}$ \\
\hline The Hackett Group (2004) & Questionnaire survey & $\begin{array}{l}\text { Focus } \\
\text { Balance } \\
\text { Scope } \\
\text { Audience } \\
\text { Technology } \\
\text { Implementation } \\
\end{array}$ \\
\hline $\begin{array}{l}\text { Papalexandris, Joannou, } \\
\text { Prastacos, and Soderquist } \\
(2005)\end{array}$ & Theoretical framework & $\begin{array}{l}\text { Preparing factors } \\
\text { Understanding factors } \\
\text { Identification factors } \\
\text { Selection factors } \\
\text { Operations factors } \\
\text { Implementations factors }\end{array}$ \\
\hline Assiri (2006) & Triangulation (survey and interview) & $\begin{array}{l}\text { Top management commitment } \\
\text { Stimulate culture } \\
\text { BSC team } \\
\text { Communicate BSC } \\
\text { Vision-mission-strategy } \\
\text { Implementation plan } \\
\text { Information system } \\
\text { Measurements assessment } \\
\text { Reward and recognition } \\
\text { Learning and innovation }\end{array}$ \\
\hline
\end{tabular}


(Table 1 continued)

\begin{tabular}{|c|c|c|}
\hline Reference & Research approach & Factors \\
\hline Chang (2009) & Case study & $\begin{array}{l}\text { Supplier/service } \\
\text { Internal process } \\
\text { Technology and planning } \\
\text { Customer measurement } \\
\text { Financial } \\
\text { Business process } \\
\text { Innovation and learning }\end{array}$ \\
\hline Chavan (2009) & Case study & $\begin{array}{l}\text { The business imperative } \\
\text { Defining competencies } \\
\text { Integrated technology } \\
\text { Customer perspective } \\
\text { Financial perspective } \\
\text { Internal business process } \\
\text { Learning and growth } \\
\end{array}$ \\
\hline Rompho (2011) & $\begin{array}{l}\text { Case study } \\
\text { interviews }\end{array}$ & $\begin{array}{l}\text { Design of the BSC } \\
\text { Clarification of mission } \\
\text { Senior management commitment } \\
\text { Involvement of employees } \\
\text { Communication process } \\
\text { Uses hardware and software system }\end{array}$ \\
\hline Biazzo and Garengo (2012) & Case study & $\begin{array}{l}\text { Develop vision and mission } \\
\text { Establish strategic objectives } \\
\text { Four perspective } \\
\text { Culture context } \\
\text { Strategy map }\end{array}$ \\
\hline Campbell et al. (2015) & & $\begin{array}{l}\text { Strategic input } \\
\text { Customer-oriented strategic outputs } \\
\text { Financial performance }\end{array}$ \\
\hline
\end{tabular}

The table above addressed 10 relevant studies on success factors of BSC implementation. Lueg and Vu (2015) reported 26 studies with high number of CSFs which suggest a BSC implementation. Across different settings of the studies, the research finds that some success factors are seen as especially relevant, i.e., top management commitment, bsc strategy, stimulate culture, bsc team, communicate bsc, implementation plan, information system, measurements assessment, learning and innovation. Kaplan stated four success factors of implementing a BSC start with top management support, employee involvement, the lead times of BSC, understanding the main goal of BSC.

However, many authors argue that the BSC could be considered as an adequate tool that may enhance and support the corporate governance (Colman, 2003; McKinsey Quarterly, 2002; Nagel \& Rigatuso, 2003). Dye (2003) claims that the BSC in corporate governance enables an organisation to support its internal and external accountability. He believes also that the BSC approach allows organisations to focus on "setting measurable governance objectives, and to report on their success in achieving these objectives". In addition, Colman (2003) reveals that by applying the BSC, organisation boards can more efficiently accomplish their responsibilities. Boards that implement the BSC will also "benefit from an enhanced ability to clearly communicate the performance information to executives, employees, and the investment community" (Colman, 2003).

\section{Research Methodology}

The descriptive research approach was used in this study to examine the elements and key factors in BSC implementation and their effectiveness, as they exist in their current state. Case studies were used in this research to investigate how BSC is being implemented in the organisations, and how it is operationalised in real 
organisational settings. A survey research method based on quantitative technique was used to provide the fundamental connection between empirical observation and mathematical expression of quantitative relationships. Most of the questions within the questionnaire were closed-ended and used a five-point Likert scale. The main objective of the questionnaire was to assess the effectiveness of BSC main elements in successful BSC project implementation (Assiri, 2006). To determine the relationship between main factors of BSC implementation (independent variables) and successful BSC project (dependent variable), and to investigate the effects of the independent variables on the dependent variable, linear regression was used (Gill $\&$ Johnson, 2010). This research is exploratory in nature, so non-probability samples are particularly relevant and suitable (Remenyi, Williams, Money, \& Schwartz, 2003). Therefore, the only criteria used for choosing the sample are those organisations that have implemented a BSC project. Furthermore, this research planned to obtain responses from different sectors and types of organisations in Saudi Arabia, therefore, generalisation of the findings could be established.

The sample unit was the managers, leaders, or BSC team who had key roles in relation to the organisation's BSC implementation. The sample size comprised 250 candidates from five organisations. The following table shows the number of responses:

Table 2

Response Rate of Study

\begin{tabular}{llll}
\hline Organisation & Distributed & Returned questionnaires & Response rate \\
\hline The Saudi American Bank (SAMBA) & 40 & 37 & 35 \\
Saudi Arabia Basic Industries Corporation (SABIC) & 65 & 60 & 57 \\
Saudi Telecom Company (STC) & 45 & 42 & 39 \\
Saudi Electricity Company (SEC) & 35 & 31 & 31 \\
Arabian American Oil Company (now Saudi ARAMCO) & 65 & 61 & 59 \\
Total & 250 & 231 & 221 \\
\hline
\end{tabular}

\section{Data Analysis}

\section{The Research Reliability}

The most popular test of inter-item consistency reliability is Cronbach's coefficient alpha $(\alpha)$ test, which reflects how well each of the items correlates with the entire scale (Table 3). Although some researchers suggest 0.7 as the accepted cut-off (Hair, Tatham, \& Anderson, 2002), a value of more than 0.6 is regarded as satisfactory (Saunders, Lewis, \& Thornhill, 2009).

Table 3

Results of Reliability Analysis With Item-Total Correlations and Cronbach's Alphas for Related CSFs

\begin{tabular}{|c|c|c|}
\hline Domain's CSFs & $\begin{array}{l}\text { Item-total } \\
\text { correlation }\end{array}$ & $\begin{array}{l}\text { Cronbach's } \\
\text { alpha }\end{array}$ \\
\hline 1-Identify BSC perspectives & & 0.8446 \\
\hline \multicolumn{3}{|c|}{ To what extent do you agree that the following are important to the organisation's BSC? } \\
\hline Financial perspective & 0.651 & \\
\hline Customer perspective & 0.843 & \\
\hline Internal business perspective & 0.682 & \\
\hline Learning and growth perspective & 0.786 & \\
\hline
\end{tabular}


(Table 3 continued)

\begin{tabular}{|c|c|c|}
\hline Domain's CSFs & $\begin{array}{l}\text { Item-total } \\
\text { correlation }\end{array}$ & $\begin{array}{l}\text { Cronbach's } \\
\text { alpha }\end{array}$ \\
\hline 2-Top management support domain's CSFs & & 0.690 \\
\hline The higher administration assumes responsibilities for BSC success & 0.526 & \\
\hline The higher administration supports the long-term BSC improvement process & 0.526 & \\
\hline The higher administration allocates adequate resources and time for the BSC project & 0.652 & \\
\hline 3-Stimulation of culture domain's CSFs & & 0.723 \\
\hline The organisation prepares and stimulates the employees' culture for BSC implementation & 0.687 & \\
\hline $\begin{array}{l}\text { The organisational culture supports and recognises the importance of exchanging knowledge } \\
\text { and experiences among the employees }\end{array}$ & 0.575 & \\
\hline There is mutual trust when employees exchange work-related information within the institute & 0.771 & \\
\hline 4-BSC team domain's CSFs & & 0.821 \\
\hline The organisation has approved a special team for the BSC project & 0.771 & \\
\hline $\begin{array}{l}\text { The BSC team members from different departments have various skills, knowledge, and } \\
\text { experiences }\end{array}$ & 0.766 & \\
\hline The BSC team is visible and has access to top management & 0.728 & \\
\hline 5-Communicate BSC domain's CSFs & & 0.745 \\
\hline The BSC is communicated throughout the organisation from the top to the low level & 0.678 & \\
\hline The organisation has good communication between different departments & 0.681 & \\
\hline The employees are well informed about BSC development continuously & 0.693 & \\
\hline 6-Mission, values, vision, strategy domain's CSFs & & .721 \\
\hline The organisation has a clear mission, values, vision, and strategy & 0.621 & \\
\hline The organisation's BSC supports the vision statement & 0.654 & \\
\hline The BSC communicated the corporate strategy throughout the organisation & 0.689 & \\
\hline The organisation clarifies and translates the vision and strategy in operational terms & 0.721 & \\
\hline 7-Training domain's CSFs & & 0.815 \\
\hline There is an emphasis placed on skills development and training in the organisation & 0.671 & \\
\hline $\begin{array}{l}\text { Knowledge and skills are developed consistently to meet the changing needs of BSC } \\
\text { implementation, teams, and individuals }\end{array}$ & 0.741 & \\
\hline The organisation links education and training of employees to its long-term plans and strategies & 0.621 & \\
\hline Top management arranges adequate resources for employee education and training & 0.782 & \\
\hline 8-Design of information system domain's CSFs & & 0.744 \\
\hline $\begin{array}{l}\text { The executive information systems in the organisation communicate BSC requirements and } \\
\text { best practice indicators }\end{array}$ & 0.503 & \\
\hline $\begin{array}{l}\text { Technology is strategy-planed and utilised to improve communication and access to service for } \\
\text { customers and stakeholders }\end{array}$ & 0.569 & \\
\hline $\begin{array}{l}\text { The organisation actively gathers, integrates, and communicates information that is critical to } \\
\text { the implementation and practice of BSC }\end{array}$ & 0.695 & \\
\hline 9-Learning and innovation domain's CSFs & & 0.784 \\
\hline $\begin{array}{l}\text { The organisation encourages employees to learn and engage in continuous professional } \\
\text { development }\end{array}$ & 0.622 & \\
\hline The learning process at operating level affects performance measurement & 0.670 & \\
\hline $\begin{array}{l}\text { There is a learning environment which encourages people to innovate and share best practice } \\
\text { and knowledge } \\
\text { The employees are encouraged to voice their opinions, criticisms, and feedback on } \\
\text { organisational functioning and performance }\end{array}$ & 0.700 & \\
\hline The organisation encourages suggestions to enhance creativity and innovation & 0.786 & \\
\hline 10-Performance evaluation domain's CSFs & & 0.792 \\
\hline The organisation evaluates the employees' performance periodically and continuously & 0.857 & \\
\hline The organisation evaluates the services it provided to their customers & 0.686 & \\
\hline The performance appraisal system encourages learning and innovation & 0.691 & \\
\hline The organisation develops its own performance and services continuously according to its need & 0.577 & \\
\hline
\end{tabular}


The most popular test of inter-item consistency reliability is Cronbach's coefficient alpha $(\alpha)$ test (Cronbach, 1984): the values of $\alpha$ range from 0 to one. The nearer the value of $\alpha$ to 1 , the better the reliability is. The correlations of each item's score with the total scale score allow investigation of whether the items measured the same construct. Table 3 shows the results from the analyses of variables. All of the scales had very high alpha scores, ranging from 0.690 to 0.844 , and were well above the generally accepted lower limit of 0.6 (Nunnally \& Bernstein, 1994). Additionally, item-total correlation values for all items were greater than 0.3 , a very satisfactory outcome according to the recommendations of Nunnally and Bernstein (1994). These findings show that these constructs may have high internal consistency and adequate reliability to consider the next stage of validity analysis.

\section{Research Validity}

Construct validity can be established through correlation analysis and by using the multivariate statistical technique of factor analysis (Hair et al., 2002). Factor analysis is used to confirm the dimensions of the concept that have been operationally defined, as well as indicate which of the items are most appropriate for each dimension, thereby testing the construct validity of the operational definitions of the variables and of the instrument. The Kaiser-Myer-Oklin (KMO) Measure of Sampling Adequacy and Bartlett's Test of Sphericity (Field, 2000), which is acknowledged as one of the best measures of determining the suitability of a set of data for subsequent factor analysis (Field, 2000), were used to examine the data in order to determine whether a factor analysis should be undertaken. According to Field (2000) and Hair et al. (2002), the value of KMO should be 0.5 or greater.

Table 4

Results of Factor Analysis

\begin{tabular}{lllll}
\hline Domains for KM-related CSFs & KMO value & Factor loading & Eigen value & \% Variance explained \\
\hline 1-Identify BSC perspectives & 0.661 & $0.880-0.781$ & 1.526 & 77.383 \\
2-Top management support & 0.655 & $0.875-0.885$ & 2.566 & 78.280 \\
3-Stimulation of culture & 0.647 & $0.840-0.840$ & 3.412 & 70.623 \\
4-BSC team & 0.578 & $0.765-0.854$ & 3.238 & 66.876 \\
5-Communicate BSC & 0.812 & $0.755-0.843$ & 2.793 & 64.830 \\
6-Mission, values, vision, strategy & 0.757 & $0.641-0.811$ & 2.339 & 58.471 \\
7-Training & 0.721 & $0.812-0.888$ & 2.172 & 72.399 \\
8-Design of information system & 0.641 & $0.895-0.803$ & 1.755 & 58.512 \\
9-Learning and innovation & 0.803 & $0.785-0.850$ & 3.565 & 64.136 \\
10-Performance evaluation & 0.682 & $0.777-0.868$ & 2.111 & 71.584 \\
\hline
\end{tabular}

As Table 4 shows in the second column, the KMO value for measurement of sample adequacy (MSA) gives the computed KMO value for each domain equal or above the acceptable level of 0.5 (Field, 2000). All factor loadings were higher than 0.5 (in the third column); therefore, each item was loaded higher on its associated construct than on any other construct. All eigen values for all domains are greater than the acceptable level of one. Also, the table shows that the respective domains for the sets of CSFs explain more than $50 \%$ of the variance for each set. In addition, all the domains are "unifactorial" and therefore, have construct validity.

\section{Results}


To assess the significance of the overall regression factors, the results of Analysis of Variance (ANOVA) were used. The linear regression was estimated with results presented in Table 5. The results show that there is a strong significant correlation between successful BSC implementation and the main elements of the conceptual framework of BSC implementation (significance of $\mathrm{F}=0.000$ ).

Table 5

Correlation Between Main Elements of BSC Implementation and Successful Factors Supporting the Implementation of BSC Project

\begin{tabular}{|c|c|c|c|c|c|c|c|c|}
\hline \multirow{2}{*}{ Independent variable } & \multicolumn{3}{|c|}{$t$-test } & \multirow{2}{*}{$-\mathrm{R}$} & \multirow{2}{*}{$\mathrm{R}^{2}$} & \multirow{2}{*}{ Adjusted $\mathrm{R}^{2}$} & \multicolumn{2}{|c|}{ ANOVA test } \\
\hline & Coefficients & $t$-value & Sig-of $t$ & & & & $\mathrm{~F}$ & $\mathrm{~F}$ \\
\hline & & & & 0.982 & 0.971 & 0.958 & 72.843 & 0.000 \\
\hline 1-Identify BSC perspectives & 0.688 & 8.920 & 0.000 & 0.688 & 0.469 & 0.463 & 79.57 & 0.000 \\
\hline 2-Top management support & 0.654 & 8.720 & 0.000 & 0.654 & 0.456 & 0.450 & 67.54 & 0.000 \\
\hline 3-Stimulation of culture & 0.754 & 7.893 & 0.000 & 0.754 & 0.667 & 0.563 & 75.84 & 0.000 \\
\hline 4-BSC team & 0.634 & 7.564 & 0.000 & 0.634 & 0.403 & 0.396 & 60.70 & 0.000 \\
\hline 5-Communicate BSC & 0.784 & 8.764 & 0.000 & 0.784 & 0.671 & 0.554 & 55.83 & 0.000 \\
\hline 6-Mission, values, vision, strategy & 0.654 & 7.823 & 0.000 & 0.654 & 0.383 & 0.376 & 65.95 & 0.000 \\
\hline 7-Training & 0.588 & 6.721 & 0.000 & 0.588 & 0.345 & 0.388 & 40.69 & 0.000 \\
\hline 8-Design of information system & 0.435 & 5.434 & 0.000 & 0.435 & 0.189 & 0.180 & 20.87 & 0.000 \\
\hline 9-Learning and innovation & 0.634 & 7.689 & 0.000 & 0.634 & 0.394 & 0.387 & 58.73 & 0.000 \\
\hline 10-Performance evaluation & 0.789 & 9.893 & 0.000 & 0.789 & 0.598 & 5.91 & 99.65 & 0.000 \\
\hline
\end{tabular}

Table 5 shows that these independent factors have explained $97.1 \%$ of the successful BSC project implementation $\left(\mathrm{R}^{2}=0.971\right)$. In addition, $t$-test results indicate a significance effect of most independent factors in successful BSC project implementation $(t<0.05)$.

\section{Identify BSC Perspective}

The linear regression result indicates that there is a positive relationship between successful BSC implementation and identifying BSC perspectives $(\mathrm{R}=68.8 \%)$. Furthermore, this factor has explained $46.9 \%$ of successful BSC implementation $\left(\mathrm{R}^{2}=0.469\right)$ and there is strong evidence that this variable has an effect on BSC implementation (significance of $t$ and $\mathrm{F}=0.000$ ).

\section{Top Management Support}

The linear regression result indicates that there is a positive relationship between successful BSC implementation and top management support $(\mathrm{R}=65.4 \%)$. Also, this factor has explained $45.6 \%$ of successful BSC implementation $\left(\mathrm{R}^{2}=0.456\right)$ and there is strong evidence that this variable has an effect on BSC implementation (significance of $t$ and $\mathrm{F}=0.000$ ).

\section{Stimulation of Culture}

The linear regression result indicates that there is a positive relationship between successful BSC implementation and stimulation of culture $(\mathrm{R}=75.4 \%)$. Furthermore, this factor has explained $56.3 \%$ of successful BSC implementation $\left(\mathrm{R}^{2}=0.563\right)$ and there is strong evidence that this variable has an effect on BSC implementation (significance of $t$ and $\mathrm{F}=0.000$ ).

\section{BSC Team}

The linear regression result indicates that there is a positive relationship between successful BSC 
implementation and a BSC team $(\mathrm{R}=63.4 \%)$. Furthermore, this factor has explained $40.3 \%$ of successful BSC implementation $\left(\mathrm{R}^{2}=0.403\right)$ and there is strong evidence that this variable has an effect on BSC implementation (significance of $t$ and $\mathrm{F}=0.000$ ).

\section{Communicate BSC}

The linear regression result indicates that there is a positive relationship between successful BSC implementation and communication of the BSC ( $\mathrm{R}=78.4 \%$ ). Also, this factor has explained $67.1 \%$ of successful BSC implementation $\left(\mathrm{R}^{2}=0.671\right)$ and there is strong evidence that this variable has an effect on BSC implementation (significance of $t$ and $\mathrm{F}=0.000$ ).

\section{Mission, Values, Vision, Strategy}

The linear regression result indicates that there is a positive relationship between successful BSC implementation and mission, values, vision, and strategy $(\mathrm{R}=65.4 \%)$. Furthermore, this factor has explained $38.3 \%$ of successful BSC implementation $\left(\mathrm{R}^{2}=0.383\right)$ and there is strong evidence that this variable has an effect on BSC implementation (significance of $t$ and $\mathrm{F}=0.000$ ).

\section{Training}

The linear regression result indicates that there is a positive relationship between successful BSC implementation and training $(\mathrm{R}=58.8 \%)$. Also, this factor has explained $34.5 \%$ of successful BSC implementation $\left(\mathrm{R}^{2}=0.345\right)$ and there is strong evidence that this variable has an effect on BSC implementation (significance of $t$ and $\mathrm{F}=0.000$ ).

\section{Design of Information System}

The linear regression result indicates that there is a positive relationship between successful BSC implementation and the design of information systems $(\mathrm{R}=43.5 \%)$. Furthermore, this factor has explained $18.9 \%$ of successful BSC implementation $\left(\mathrm{R}^{2}=0.189\right)$ and there is strong evidence that this variable has an effect on BSC implementation (significance of $t$ and $\mathrm{F}=0.000$ ).

\section{Learning and Innovation}

The linear regression result indicates that there is a positive relationship between successful BSC implementation, and learning and innovation $(\mathrm{R}=63.4 \%)$. In addition, this factor has explained $39.4 \%$ of successful BSC implementation $\left(\mathrm{R}^{2}=0.394\right)$ and there is strong evidence that this variable has an effect on BSC implementation (significance of $t$ and $\mathrm{F}=0.000$ ).

\section{Performance Evaluation}

The linear regression result indicates that there is a positive relationship between successful BSC implementation and performance evaluation $(\mathrm{R}=78.9 \%)$. Furthermore, this factor has explained $59.1 \%$ of successful BSC implementation $\left(\mathrm{R}^{2}=0.591\right)$ and there is strong evidence that this variable has an effect on BSC implementation (significance of $t$ and $\mathrm{F}=0.000$ ).

\section{Ranking Analysis}

In order to assess the significance level of the $10 \mathrm{CSF}$ that have been identified based on the literature review, Table 6 shows the mean and standard deviation for the 10 CSFs, in descending order of importance. 
Table 6

Mean Ranking CSFs and One-Sample t-Test of Statistical Significance of BSC CSFs

\begin{tabular}{lllllll}
\hline \multirow{2}{*}{ Rank } & CSF & \multirow{2}{*}{ Mean } & Std deviation & \multicolumn{3}{c}{ Test value $=3$} \\
\cline { 5 - 6 } & & & & & S Sig. (2-tailed) & Mean difference \\
\hline 1 & Identify BSC perspectives & 4.82 & 0.431 & 55.765 & 0.000 & 1.8821 \\
3 & Top management support & 4.78 & 0.312 & 57.692 & 0.000 & 1.8762 \\
4 & BSC team & 4.61 & 0.653 & 24.087 & 0.000 & 1.7876 \\
5 & Mission, values, vision, strategy & 4.53 & 0.754 & 35.876 & 0.000 & 1.5992 \\
6 & Training & 4.48 & 0.867 & 28.387 & 0.000 & 1.5565 \\
7 & Communicate BSC & 3.95 & 0.618 & 24.876 & 0.000 & 1.5129 \\
8 & Performance evaluation & 3.82 & 0.872 & 22.654 & 0.000 & 1.4893 \\
9 & Design of information system & 3.76 & 0.734 & 18.487 & 0.000 & 1.4654 \\
10 & Learning and innovation & 3.72 & 0.865 & 20.654 & 0.000 & 1.3762 \\
\hline
\end{tabular}

Table 6 shows that the CSFs were ranked in the range between 3.5 and 4.8, representing a considerable level of criticality. Identifying BSC perspectives and top management support was viewed as the most critical success factor by responding organisations, as seen in the mean values of 4.82 and 4.78 respectively.

Furthermore, the results from one-sample $t$-test conducted to determine whether these observed means of the CSFs are significantly different from the mid-point 3.0 in Table 6, were found significant differences between these means and their mid-points $3.0(p<0.00)$. This confirms that all critical factors for BSC implementation are on the positive side.

\section{Discussion and Conclusion}

Within this study, the effects of critical factors in BSC implementation were empirically tested. Based on the survey, the results indicate that all BSC implementation factors suggested in the present study are critical. The analysis shows that all the factors of the BSC are significant. However, it is crucial to address all these critical factors simultaneously for successful implementation. In essence, failure in one factor can affect the overall BSC project implementation.

Based on the present study analysis, the BSC factors can be discussed as follows. The study results confirm that identification of adequate BSC perspectives significantly influences the successful implementation of the BSC. This result is consistent with previous study findings (Kaplan \& Norton, 2001; Kaplan, 2010). However, the choice of perspectives for the organisation's BSC must adhere to what is necessary to execute the strategy and create a competitive advantage for the organisation.

Top management support and commitment significantly influence the BSC's successful implementation; the commitment must be continuous, and top management's full support is needed for the BSC team. This result is consistent with previous study findings (Kaplan \& Norton, 2001; D. Karathanos \& P. Karathanos, 2005; Assiri, 2006). In addition, top management must provide the BSC project with all resources required.

The BSC team significantly influences its successful implementation. This result is consistent with previous study findings (Kaplan \& Norton, 2001; 2008; Urrutia \& Eriksen, 2005). However, the BSC team has to be supported continuously by top management to enable them to sustain and maintain the BSC.

The existence of a clear mission and strategy also significantly influences the BSC's successful implementation. This result is consistent with previous study findings (D. Karathanos \& P. Karathanos, 2005; 
Kaplan \& Norton, 2008; Kaplan, 2010). However, the BSC measures must be linked to the strategic objectives of the organisation.

Training programmes significantly influence the successful implementation of the BSC. This result is consistent with previous study findings (Urrutia \& Eriksen, 2005; Assiri, 2006). The BSC is essentially a new approach to the organisation. It is about adopting new perspectives and processes, and about innovation and change. Consequently, employees' training and education initiatives may help to facilitate this change by providing employees with the knowledge and skills they require to adapt and to lead this change process.

Communicating about the BSC significantly influences its successful implementation. This result is consistent with previous study findings (Evans, 2005; Assiri, 2006). However, the organisation must set up a comprehensive and sustained plan to communicate the BSC to its employees. A well-structured communication plan will facilitate the implementation of the BSC.

Learning and innovation also significantly influences the successful implementation of the BSC. This result is consistent with previous study findings (Kaplan \& Norton, 2001; 2008; Brewer et al., 2004; Assiri, 2006). However, the organisation must utilise learning and innovation from previous experiences of BSC implementation. Frequent review and discussion of BSC results needed to ensure success.

The way in which an organisation designed its information systems significantly influences the successful implementation of the BSC. This result is consistent with previous study findings (Kaplan, 2010; Assiri, 2006).

Performance evaluation by management also significantly influences the successful implementation of the BSC. This result is consistent with previous study findings (Kaplan \& Norton, 2001; Assiri, 2006; Long et al., 2015). To promote BSC success management should update performance evaluation and measures according to new internal or external circumstances.

Stimulation of organisational culture significantly influences the successful implementation of the BSC. This result is consistent with previous study findings (Kaplan \& Norton, 2001; Assiri, 2006). However, all levels of the organisation must be prepared prior to introduce the BSC, starting at the top and permeating the whole organisation. All levels should be aware of the significance of the BSC and its future benefits. Organisations, therefore, need to create a culture where all employees can participate and be involved in the BSC programmes relevant to their workplace.

\section{References}

Amaratunga, D., \& Baldry, D. (2002). Moving from performance measurement to performance management. Facilities, Bradford, 20(5/6), 217-223.

Assiri, A. (2006). The implementation of the balanced scorecard, an empirical study and a proposed generic model based on best practice (unpublished Ph.D. thesis). School of Management, University of Bradford.

Biazzo, S., \& Garengo, P. (2012). Performance measurement with the balanced scorecard: A practical approach to implementation within SMEs. Heidelberg, Berlin: Springer-Verlag.

Brewer, P. C., Albright, T., \& Davis, S. (2004). Security regional bank: Implementing a balanced scorecard using the business modelling approach. Journal of Corporate Accounting and Finance, 15(5), 73-84.

Campbell, D., Datar, S. M., Kulp, S. L., \& Narayanan, V. G. (2015). Testing strategy with multiple performance measures: Evidence from a balanced scorecard at store 24. Journal of Management Accounting Research, 27(2), 39-65.

Chang, H. (2009). An empirical study of evaluating supply chain management integration using the balanced scorecard in Taiwan. The Service Industries Journal, 29(2), 185-202.

Chavan, M. (2009). The balanced scorecard: A new challenge. Journal of Management Development, 28(5), 393-406.

Colman, R. (2003). CMA balance and accountability. CMA Management, 76(9), 3.

Cronbach, L. J. (1984). Essentials of psychological testing (4th ed.). New York: Harper and Row. 
Davis, S., \& Albright, T. (2004). An investigation of the effect of balanced scorecard implementation on financial performance. Management Accounting Research, 15, 145-153.

De Waal, A. (2002). Quest for balance: The human element in performance management systems. New York, UK: Wiley.

Dye, R. W. (2003). Keeping score: By measuring and improving the performance of company boards. CMA Management, 76(9), 18.

Evans, N. (2005). Assessing the balanced scorecard as a management tool for hotels. International Journal of Contemporary Hospitality Management, 17(5), 376-390.

Field, A. (2000). Discovering statistics using SPSS for windows: Advanced techniques for the beginner. London: SAGE.

Geuser, F., Mooraj, S., \& Oyon, D. (2009). Does the balanced scorecard add value? Empirical evidence on its effect on performance. European Accounting Review, 18(1), 93-122.

Gill, J., \& Johnson, P. (2010). Research methods for managers (4th ed.). London: SAGE.

Hair, J. F., Tatham, R. L., \& Anderson, R. E. (2002). Multivariate data analysis. London: Prentice-Hall PTR; NJ: Upper Saddle River.

Ho, I. H., Cheng, T. F., \& Lin, C. Y. (2001). The construction of the performance evaluation model for engineering educational systems. International Conference on Engineering Education, Oslo.

Ittner, C. D., \& Larcker, D. F. (2003). Coming up short on nonfinancial performance measurement. Harvard Business Review, 81(11), 88-95.

Jochem, R., Menrath, M., \& Landgraf, K. (2010). Implementing a quality-based performance measurement system: A case study approach. The TQM Journal, 22(4), 410-422.

Kaplan, R. (2010). Conceptual foundations of the balanced scorecard. Working Paper, Harvard Business School, Boston, MA17 March.

Kaplan, R. S., \& Norton, D. P. (1996). Using the balanced scorecard as a strategic management system. Harvard Business Review, 74(1), 75-85.

Kaplan, R. S., \& Norton, D. P. (2001). The strategy-focused organisation: How balanced scorecard companies thrive in the new business environment. Boston, MA: Harvard Business School Press.

Kaplan, R. S., \& Norton, D. P. (2008). Execution premium: Linking strategy to operations for competitive advantage. Boston: Harvard Business School Press.

Karathanos, D., \& Karathanos, P. (2005). Applying the balanced scorecard to education. Journal of Education for Business, 80(4), $222-230$.

Long, J. H., Mertins, L., \& Vansant, B. (2015). The effects of firm-provided measure weightings on evaluators' incorporation of non-contractible information. Journal of Management Accounting Research, 27(1), 47-62.

Lueg, R., \& Vu, L. (2015). Success factors in balanced scorecard implantation-A literature review. Management Revue, 26(4), 306-327.

McKinsey Quarterly. (2002). Just-in-time strategy for a turbulent world (special edition). Risk and resilience, 16-27.

Nagel, M. E., \& Rigatuso, C. (2003). Improving corporate governance: A balanced scorecard approach. Balanced Scorecard Collaborative, Inc.

Niven, P. R. (2008). Balanced scorecard step-by-step for government and nonprofit agencies. Hoboken, NJ: John Wiley \& Sons Inc.

Nunnally, J., \& Bernstein, I. (1994). Psychometric theory. New York \& London: McGraw-Hill.

Papalexandris, A., Joannou, G., Prastacos, G., \& Soderquist, K. E. (2005). An integrated methodology for putting the balanced scorecard into action. European Management Journal, 23(2), 214-227.

Remenyi, D., Williams, B., Money, A., \& Schwartz, E. (2003). Doing research in business and management: An introduction to process and method. London: SAGE.

Rompho, N. (2011). Why the balanced scorecard fails in SMEs: A case study. International Journal of Business and Management, 6(11), 39-46.

Saunders, M., Lewis, P., \& Thornhill, A. (2009). Research methods for business students (5th ed.). Harlow, UK: Pearson Education Limited.

The Hackett Group. (2004). World-class IT organisations spend less yet deliver more-Effective outsourcing among success factors. [online] available at http://www.businesswire.com/news/home/20040615005830/en/Hackett-Group-World-Class-Organizations-Spend-Deliver (accessed 15 May 2016) 
Tyagi, R., \& Gupta, P. (2008). Complete and balanced service scorecard creating value through sustained performance improvement. New Jersey: Pearson Education.

Urrutia, I., \& Eriksen, S. (2005). Application of the balanced scorecard in Spanish private health-care management. Measuring Business Excellence, 9(4), 16-26.

Valiris, G., Chytas, P., \& GlyKas, M. (2005). Making decisions using the balanced scorecard and the simple multi-attribute rating technique. Performance Measurement and Metrics, 6(3), 159-171.

Van Grembergen, W., \& De Haes, S. (2005). Measuring and improving IT governance through the balanced scorecard. Information Systems Control Journal, 2(1), 35-42.

Wang, W. (2005). An evaluation of the balanced scorecard? In equity valuation: The case of exchange ration in the M\&Ms of Taiwan's financial industry. Journal of Intellectual Capital, 6(2), 206-221.

$\mathrm{Wu}$, A. (2005). The integration between balanced scorecard and intellectual capital. Journal of Intellectual Capital, 6(2), $267-284$. 